Jean-Louis Berger

University of Geneva

Nadine Kipfer

Swiss Pedagogical Institute for Vocational Training

Fredi Büchel

University of Geneva

\title{
Effects of Metacognitive Intervention in Low-Performing Vocational Students
}

\begin{abstract}
The objective of this study was to evaluate the efficacy of a teacheradministered metacognitive training module on the performance and strategy-use of vocational students considered as "slow learners." Prior to the experiment all experimental teachers underwent an extended training. Moreover, they received all didactic materials of the training module as well as several mediation guides. The progress made by the trained students was controlled by a quasi-experimental design including a pretest, an immediate posttest, and a delayed posttest. The training module, both composed of decontextualized and school-related tasks, was taught in a class setting. The EG1 applied the whole training module in a prescribed way. The efficacy of this training is compared to that of an EG2 group whose teachers received the same training as the teachers of the EG1, but they were free to choose only specific parts of the module, instead of the training in its entirety, and to follow the mediation guides in a less rigorous fashion. Both experimental groups were compared to a control group that did not follow any specific training. The results show that the training module had significant effects on the students' performance in multiple domains and on the quality and quantity of strategies used. An analysis in terms of gain scores revealed an association between improvement in performance and improvement in strategy use, suggesting that the acquisition of strategies may be responsible for better performance.
\end{abstract}

Key words: learning difficulties, vocational education, cognitive education, metacognition

As students in vocational education are generally not among the most successful students in secondary education, vocational education is considered an option for those who are less academically oriented. In Switzerland, vocational students who demonstrate important learning difficulties are referred to a less demanding professional training (i.e., 
a 2-year vocational training track that is more practically oriented instead of a classical 3- or 4-year one). Most of these students have significant academic shortcomings and could be characterized as "slow learners" (Borkowski \& Day, 1987; Masi, Marcheschi, \& Pfanner, 1998). They are intellectually borderline (IQ between 71 and 84) according to the DSM-IV (American Psychiatric Association, 1994), perform poorly at school and are not eligible for special education. A substantial number of these students are immigrants and their first language is not the local one. In addition, some of them suffer from psychological illness or social deprivation. These factors cause problems both in pursuing a school career and integrating professionally. A large number of these students may be unable to fulfill the conditions stipulated for obtaining the professional diploma delivered by the Federal Office for Professional Education and Technology. This could be due to various reasons, but most notably for their learning difficulties (differences between persons with learning difficulties, i.e., slow learners, and persons with learning disabilities have been discussed previously in Büchel, 2003). In fact, some of these students are characterized by their teachers as very passive when confronted with learning tasks (Elke et al., in press). For example, they seldom, if ever, ask themselves questions, do not plan their solution, and rarely apply learning or problem solving strategies. Our central hypothesis is that these students can become more self-regulated learners (i.e. use strategies) if they are given the opportunity to apply more metacognitive control, metacognitive knowledge, and cognitive strategies (Weinstein, Husman, \& Dierking, 2000). Therefore, we developed a training module aimed at these objectives. In this paper, we briefly report theoretical foundations of the module and its content.

\section{Theoretical Rationale of the Metacognitive Training Approach}

Since its introduction by Flavell $(1971,1976)$ and Brown (1978), the concept of metacognition represents a broad research domain in the psychology of learning. While metamemory was the first researched, metacognition is currently as widely applied to school domains such as, text comprehension (Veenman \& Beishuizen, 2004), writing (Graham \& Harris, 2005) and mathematics problem solving (Montague, 2007). Metacognition is generally subdivided into two components: metacognitive knowledge (or metaknowledge) and metacognitive strategies. The first refers to knowledge the learner has about himself (e.g., his weaknesses), about tasks (e.g., what makes a task difficult), about strategies (e.g., how useful a certain strategy can be), and about the interaction between himself, tasks, and strategies (Cavanaugh \& Perlmutter, 1982; Flavell \& Wellman, 1977). Metacognitive strategies refer to the monitoring and regulation of learner cognitive functioning (Borkowski, Chan, \& Muthukrishna, 2000). It is composed of anticipative, planning, and controlling activities. Metacognitive knowledge and metacognitive strategies are considered interdependent: the first forms the basis for the second and development of the second permits development of the first (Brown, 1987). Metacognitive strategies are guided by the student's metaknowledge; this knowledge is also at the origin of strategy selection and strategy use.

Both components of metacognition have been described as underdeveloped in students with learning difficulties or mental retardation (e.g., Borkowski, Reid, \& Kurtz, 1984; Montague, 1998; Swanson, 1993). Therefore, researchers have tried to improve both metacognitive strategies and metaknowledge.

Training of metacognitive components in low-performers has produced encouraging results (e.g., Montague, 1998). In mathematics problem solving and arithmetic, several 
recent training programs for group administration, based mainly on improvement of metacognitive strategies and metaknowledge development, yielded substantial gains in performance for students in primary and secondary education (Mevarech \& Fridkin, 2006; Montague, 2007; Van Luit \& Kroebergen, 2006). Moreover, a more general training for vocational students proved to be efficient in improving students' learning and problem-solving strategies (Büchel, Grassi, Scharnhorst, \& Ghilardi, 2002). Implementation of metacognitive training or metacognitive instruction in the classroom is, however, a difficult task. Following the outline set forth by Pressley, Goodchild, Fleet, Zajchowski, and Evans (1989), metacognitive instruction should include an introductory phase and allow for the practice of a range of domain-specific, as well as general strategies, and the development of metaknowledge about strategies. Teachers of low-performing students would need to be especially trained in applying this type of instruction (notably by using metacognitive prompting; Hoffman \& Spatariu, 2008) and be able to handle such a challenge.

Two important points to be considered when preparing a metacognitive training for lowperformers are the generality and the contextualization of the strategy to be trained. In fact, strategy transfer has to be anticipated when administrating training on metacognition so that students can generalize their progress to various school subjects. This is essential for low-performers because they typically have considerable difficulty with strategy transfer (Borkowski et al., 1984).

Wong (1993) advocates the instruction of subject-specific strategies instead of general strategies. His primary reasoning is that students show large difficulties in applying general strategies to school-specific tasks. Secondly, if students perceive the link between the strategy and school task, they are more predisposed to learn and apply the strategy readily. However, subject-specific strategies can remain embedded in the specific subject; in this case they are difficult to transfer. On the other hand, general strategies may also be instructed by the use of decontextualized tasks (not directly linked to any school subject). As well, the transfer of the general strategies to different contexts can be prepared with the presentation of school-related tasks (Klauer \& Phye, 1994). In the case of metacognitive strategy training, these strategies are considered to be general because they are applicable in virtually every school subject. Training aimed at their improvement should, consequently, offer a variety of tasks in order to give the students opportunities to transfer these general strategies. One way to facilitate students' strategy transfer is through the rotation of tasks characterized as decontextualized and contextualized (specific to a certain school subject). This is the position we adopted for the application of the training. The advantages of this alternation are mentioned below in the description of the training module.

\section{Research Goals}

The aim of this research was to implement and evaluate a training module composed of cognitive and metacognitive components, focused on learning difficulties, to take into consideration both conative and cognitive factors. This paper is focused solely on the cognitive aspects. The module consisted of 12 45-minute lessons, each given in a classroom setting, aimed at the development of learning strategies, problem solving strategies, and metacognitive strategies. In order to confront students with their own learning style, they worked on decontextualized exercises during the first 2 sessions. They learned to better adapt their strategies to personal needs and the task specificity. 
Afterwards, they also learned to transfer those strategies to academic tasks (text comprehension, exercises, and mathematics problem solving).

\section{The Cognitive-Metacognitive Training Module}

The intervention program was composed of decontextualized and contextualized exercises. Six lessons were based on decontextualized materials and four lessons used Windows and Broken up figures tasks from the DELV program (Das Eigene Lernen Verstehen [understanding one's own learning processes]; Büchel \& Büchel, 1997; Klauer, 2002). DELV is a metacognitively oriented program aimed at the improvement and activation of cognitive and metacognitive strategies in learning and reasoning. Although this program is composed of eight different sets of paper-and-pencil tasks, only two of them were applied in this training module. In Windows (see Figure A1 in Appendix for an example), "a picture is presented to the student together with eight windows (small parts copied from the picture). The student has to identify the windows in the picture.” (Büchel \& Büchel, 1997, p. 46) This type of exercise gives the student the opportunity to acquire, with the help of a mediator, attention focusing, verbal labeling, and short-term memory management strategies. In Broken up figures (see Figure A2 in Appendix for an example), "a model is broken down into two or three parts which are presented among a number of distracters (...) the student has to find the parts which make up the model” (Büchel \& Büchel, 1997, p. 46). Such tasks aim to develop the verbal support of mental imagery and systematic exploration. Besides the acquisition of the aforementioned cognitive strategies, the DELV tasks also served to stimulate metacognitive strategies: anticipation (e.g. reflect about the difficulty of the task), planning (what strategies and what steps are needed to solve the task), and control (checking during as well as after task solving).

Two of the lessons used several tasks from the Instructions instrument (see Figure A3 in Appendix for an example) in the program Instrumental Enrichment (Feuerstein, Rand, Hoffman, \& Miller, 1980). The objective of these tasks was to help the student become aware of his or her processing of instructions. Ideally, the students would learn to analyze instructions (e.g., what is the goal of the task), to check their understanding (control their comprehension), and to follow these processes systematically (plan and check). In these six decontextualized lessons, students reflected on their own learning style, optimized acquired strategies, complemented them with new ones, consolidated them, and executed near transfers onto similar exercises. Non-school-related tasks were used for two main reasons. First, this allowed the focus to remain on the learning processes and strategies, instead of shifting to the content of the task or its product (Büchel \& Scharnhorst, 2000; Feuerstein, Feuerstein, \& Schur, 1997). The additional reason non-school related tasks were used was that the strategies could be learned with material that is neutral in terms of affective reactions (i.e., anxiety is reduced because negative self-perceptions due to previous failures on school tasks are avoided; Bandura, 1997).

The six lessons of contextualization were composed of mathematics problem solving (see Figure A4 in Appendix for an example) and text comprehension exercises. The latter were composed of short, complex texts. These tasks were developed by Büchel and Molo (2000) and were adapted from previous research with children from 10- to 12-yearold. In the text comprehension, students would have to go back to understand a story, take notes, and/or draw an outline to fully remember all the information from the story. On a cognitive level, these tasks help students to develop note-taking, outlining, 
paraphrasing skills and foster selective re-reading. On the metacognitive level, students learn to estimate the level of difficulty and apply metacognitive strategies, especially the control of comprehension. As well, students learn to transfer the strategies acquired in a decontextualized environment to school subjects and find strategies appropriate for the task. Table 1 gives an overview of the lessons.

Table 1. Cognitive-Metacognitive Intervention Module

\begin{tabular}{|c|c|c|}
\hline Lesson & Cognitive strategy & Type of task \\
\hline $1-2$ & Activation and acquisition of strategies & DELF Windows + Broken up fig. \\
\hline 3 & Transfer of strategies & Math problem solving \\
\hline $4-5$ & $\begin{array}{l}\text { Consolidation and adaptation of } \\
\text { individual strategies }\end{array}$ & DELF Windows + Broken up fig. \\
\hline 6 & Transfer of strategies & Math problem solving \\
\hline 7 & Activation and acquisition of strategies & $\begin{array}{l}\text { Instrumental Enrichment (IE): } \\
\text { Instructions }\end{array}$ \\
\hline 8 & Transfer of strategies & Text comprehension \\
\hline 9 & $\begin{array}{l}\text { Consolidation and adaptation of } \\
\text { individual strategies }\end{array}$ & IE: Instructions \\
\hline $10-11$ & Transfer of strategies & Text comprehension \\
\hline 12 & Transfer of strategies & Math problem solving \\
\hline
\end{tabular}

The intervention sessions were administered by professional and experienced teachers trained through a 5-day course on cognitive education for low-performing vocational students. The teachers were supervised by the researchers. Therefore, the project also contributed to complementary in-service teacher education. The students' improvement was assessed using a pretest and posttest research design. The effectiveness of the metacognitive training module (experimental group 1 [EG1]) was compared not only to a control group (CG), that did not follow any training, but also to a training that we qualify as "implicit" because it was given by teachers trained by the researcher (experimental group 2 [EG2]). The teachers in EG2 did not explicitly apply the training module like the teachers from EG1 did, but were instructed to use only some of the materials from the metacognitive training program (see Table 1). Furthermore, they were asked to apply the principles of metacognitive prompting and use the mediation guides (described below in detail) that had been provided and presented during the teacher training. Each teacher in EG2 used some of the DELV tasks (Windows), but also some other tasks he/she usually gives to his/her students. They used a teaching style similar to the style they learned in the 5-day course (see Table 5 for an illustration of this teaching style). EG2 also worked to develop their students' metacognitive strategies. The introduction of this second type of training allows for an assessment in the effectiveness of a structured training (the training module) compared to "implicit” training. 


\section{Research Questions and Hypotheses}

The study was guided by the postulation that, after class training, EG1 would show higher achievement than EG2 and CG in all dependent variables of interest (i.e., strategy use and performance in mathematics problem solving, in text comprehension, and in a school-related lesson). Additionally, the EG2 would show higher achievement in these same variables than the CG. This expectation was warranted by the fact that their teachers did apply some metacognitive prompting principles taught at the 5-day teacher training course even if they did not apply the full training module.

The following three research questions were formulated:

Question 1. Explicit class application of the training module. If the training module (12 lessons of 45 minutes each) is explicitly applied by a teacher of the EG1, do the students (at the end of the training and 8 weeks later):

a. Apply higher levels of cognitive and metacognitive strategies in text comprehension and mathematics problems solving exercises?

b. Show higher learning and problem solving performance in text comprehension and mathematics problems solving exercises?

c. Apply higher levels of cognitive and metacognitive strategies in a school-related lesson? (far transfer effects)

d. Show higher learning performance in a school-related lesson? (far transfer effects)

Question 2. Implicit effects of the 5-day course. If metacognitive prompting principles (during 12 lessons of 45 minutes each) are applied by a teacher of the EG2, do the students (at the end of the training and 8 weeks later) show the same learning and transfer effects as the students with explicit class application of the training module?

Question 3. Inter-individual differences in performance improvement and relation to strategy use and cognitive abilities:

a. Is the improvement in performance linked to an improvement in strategy use?

b. How can cognitive abilities explain this improvement?

\section{Teacher Training}

\section{Method}

The aims of teacher training were to provide a theoretical base in cognitive education, learning, and motivational strategies; as well as, semi-standardized teaching methods developed to increase learning capacity in vocational students with learning difficulties. For five days (once a week), the participants experimented with teaching materials and simulated (role played) mediation situations (e.g., problem solving with mediation).

\section{Participants}

Three teachers that followed the 5-day course participated with their classes in the research as EG1 (those who applied the whole training module in a prescribed way) and four teachers, and their classes, formed the other experimental group, EG2 (those who applied only parts of the training module in a free way). Finally, three classes served as the control group and took part only in the pre- and posttest phases (CG). The teachers in the CG were not enrolled at the 5-day course and were not informed about the content of 
the course. These teachers simply kept teaching their curriculum normally. The main differences between the three groups are resumed in Table 2. Characteristics of the participants (classes) are presented in Table 3.

Table 2. Description of the three groups

\begin{tabular}{|c|c|c|}
\hline \multicolumn{2}{|c|}{ Experimental groups } & \multirow[t]{2}{*}{ Control group (CG) } \\
\hline (EG1) & (EG2) & \\
\hline \multicolumn{3}{|c|}{ Teacher training and information } \\
\hline $\begin{array}{l}5 \text { day teacher training } \\
\text { Full information } \\
\text { concerning the research } \\
\text { goals and hypotheses }\end{array}$ & $\begin{array}{l}5 \text { day teacher training } \\
\text { Full information } \\
\text { concerning the research } \\
\text { goals and hypotheses }\end{array}$ & $\begin{array}{l}\text { no teacher training } \\
\text { Information about the } \\
\text { research goals but no } \\
\text { information concerning } \\
\text { the hypotheses }\end{array}$ \\
\hline \multicolumn{3}{|c|}{ Materials, training lessons, and supervision } \\
\hline $\begin{array}{l}\text { Apply all } \\
\text { decontextualized and } \\
\text { contextualized training } \\
\text { materials prepared by the } \\
\text { research group }\end{array}$ & $\begin{array}{l}\text { Apply some of the } \\
\text { training materials } \\
\text { prepared by the research } \\
\text { group }\end{array}$ & $\begin{array}{l}\text { Apply no training } \\
\text { materials prepared by the } \\
\text { research group but } \\
\text { regular school materials }\end{array}$ \\
\hline $\begin{array}{l}\text { Teach the training } \\
\text { module in explicit } \\
\text { training lessons }\end{array}$ & $\begin{array}{l}\text { Integrate parts of the } \\
\text { training module in } \\
\text { regular school lessons }\end{array}$ & $\begin{array}{l}\text { Teach regular school } \\
\text { matters }\end{array}$ \\
\hline $\begin{array}{l}\text { Are supervised by the } \\
\text { research group }\end{array}$ & $\begin{array}{l}\text { Are supervised by the } \\
\text { research group }\end{array}$ & No supervision \\
\hline
\end{tabular}

The research sample was very heterogeneous, students came from different Swiss vocational schools in four French-speaking cantons. Among the 84 student sample, 54 were male, while 30 were female. The sample was very diverse, with 20 different nationalities, as well as, 14 different languages represented. The mean student age of the sample was 18 years and 8 months. The students were all enrolled in a 2-year vocational training program where they presented markedly low scores in nonverbal IQ, vocabulary knowledge, and arithmetic abilities tests (for a description of their cognitive abilities, see below). Experimental mortality was rather high, with 21 students missing from the delayed posttest. This was mostly commonly caused by students being fired by their employer; while some others had changed their professional projects. It has been documented that low track students in vocational education in Switzerland have a high dropout risk (e.g. Schmid \& Stalder, 2007). 
Table 3. Sample Characteristics

\begin{tabular}{|c|c|c|c|c|c|c|}
\hline \multirow{2}{*}{$\begin{array}{l}\text { Group } \\
\text { EG1 }\end{array}$} & \multirow[t]{2}{*}{$n$} & \multirow{2}{*}{$\begin{array}{c}\text { Age } \\
M(S D)\end{array}$} & \multicolumn{2}{|c|}{ Sex } & \multicolumn{2}{|c|}{ Nationality } \\
\hline & & & Male & Female & Swiss & Foreigners \\
\hline Class 1 & $9 / 6 / 6$ & $18 ; 6(1 ; 4)$ & 9 & 0 & 5 & 4 \\
\hline Class 2 & $8 / 5 / 5$ & $16 ; 4(0 ; 6)$ & 5 & 3 & 1 & 7 \\
\hline Class 3 & 13 / 12 / 12 & $18 ; 5(1 ; 7)$ & 2 & 11 & 9 & 4 \\
\hline Total & 30 / 23 / 23 & $17 ; 10(1 ; 7)$ & 16 & 14 & 15 & 15 \\
\hline \multicolumn{7}{|l|}{$E G 2$} \\
\hline Class 4 & $8 / 7 / 6$ & $17 ; 8(2 ; 6)$ & 8 & 0 & 1 & 7 \\
\hline Class 5 & $11 / 10 / 8$ & $16 ; 3(0 ; 6)$ & 5 & 6 & 4 & 7 \\
\hline Class 6 & $5 / 3 / 3$ & $18 ; 8(0 ; 8)$ & 2 & 3 & 3 & 2 \\
\hline Class 7 & $8 / 6 / 1$ & $16 ; 11(0 ; 7)$ & 2 & 6 & 1 & 7 \\
\hline Total & $32 / 26 / 18$ & $17 ; 3(1 ; 5)$ & 17 & 15 & 9 & 23 \\
\hline \multicolumn{7}{|l|}{$C G$} \\
\hline Class 8 & $8 / 4 / 4$ & $18 ; 6(1 ; 2)$ & 8 & 0 & 2 & 6 \\
\hline Class 9 & $8 / 8 / 8$ & $18 ; 8(1 ; 7)$ & 8 & 0 & 5 & 3 \\
\hline Class 10 & $6 / 5 / 5$ & $18 ; 10(2 ; 3)$ & 5 & 1 & 3 & 3 \\
\hline Total & 22 / 17 / 17 & $18 ; 8(1 ; 7)$ & 21 & 1 & 10 & 12 \\
\hline
\end{tabular}

Note. Concerning the number of students in each class $(n)$, the first number refers to participants at the pretest, the second at the immediate posttest and the third at the delayed posttest. Mean age (years; months and SD in parentheses), sex, and nationality refer to characteristics of participants at the pretest.

\section{Design}

All tests were group tests and administered in class. The pretest was administered at the end of the year (December, 2006). During the first week of January, teachers of the experimental groups received the training materials. EG1 teachers then presented the 12 lessons of the metacognitive training module, one lesson a week. At the end of the last lesson, the first posttest (referred to as the immediate posttest below) was administered by the researchers. Teachers in the EG2 enriched their courses and teaching style by principles of metacognitive prompting and applied various tasks suggested in the module. In order to control the activities of the teachers, supervision by the researchers also took place in this group. Interviews at the end of the training revealed that each teacher in EG2 had used between four and six lessons among those comprised in the module. Fourteen weeks after the pretest, the immediate posttest took place (in April, 2007); the delayed posttest was carried out 8 weeks after the immediate posttest (June, 2007). Table 4 outlines the experimental design and tests administered at each phase. 
Table 4. Experimental Design and Tests

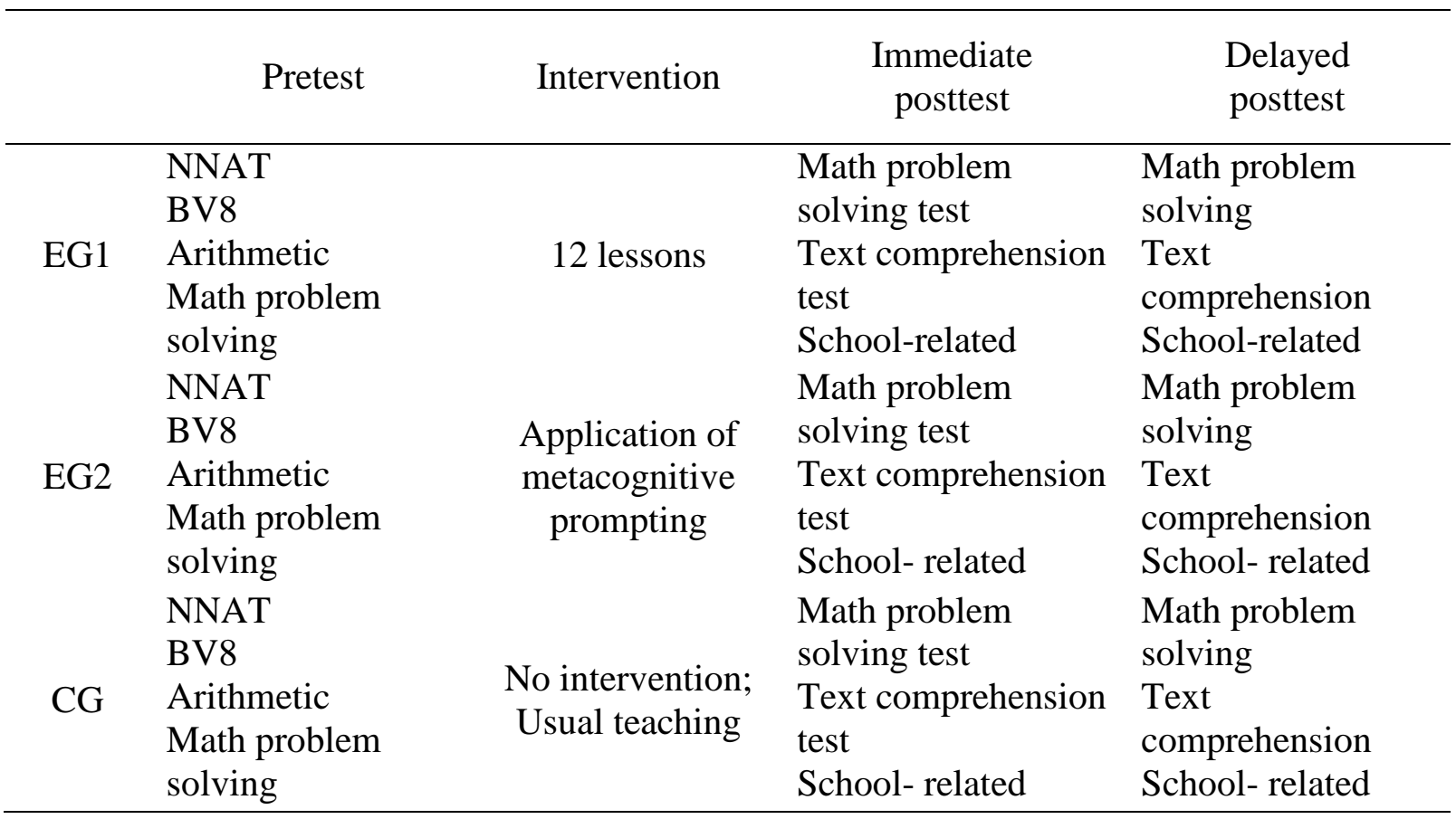

Note. NNAT $=$ Naglieri Nonverbal Achievement Test; BV8 = Bonnardel's vocabulary test.

\section{Instruments}

\section{Cognitive Abilities Tests}

The following instruments were administered at the pretest only, in order to assess the group equivalence with regard to cognitive abilities. The scores of these tests were later used as covariates in the statistical analyses.

Naglieri Nonverbal Achivement Test (NNAT ; Naglieri, 1998). The NNAT, which measures nonverbal reasoning, provides a language-free means of measuring a student's general ability through the use of nonverbal stimuli. It is especially valuable for the assessment of adolescents from diverse linguistic and cultural backgrounds. The test is composed of 38 multiple-choice items and is administered in a group situation for 30 minutes. We used the $\mathrm{G}$ form for students between 15 and 17 years old. Internal consistency of the score in our sample was $\alpha=.86$. The score on the NNAT is considered to indicate low IQ.

Bonnardel's Test of Vocabulary Knowledge (BV8). This test is composed of 50 items. For each item, a set of six words is suggested; five of them are closely related and the sixth word is distinctly different. The task is to identify this deviating word. The authors report an internal consistency of $\alpha=.86$ and a stability (test-retest) of $r=.86$ (with a mean delay of 8 weeks). Convergent validity of the test has been confirmed with the French version of the Mill-Hill (Deltour, 1998). Internal consistency of the score in our sample was $\alpha=.81$. 
Arithmetic ability test. We developed an arithmetic test on the basis of the Rechentest [Calculation test] (Lobeck, 1990) intended for children in the fourth to sixth primary grades. The test consists of calculations on: the four operations, situations with and without decimals, the conversion of units, and items covering the rule of three. Twenty minutes were given to complete 24 items. Internal consistency of the score in our sample was $\alpha=.78$.

\section{School Tests}

Our area of interest focuses on two aspects relative to the tasks: the students' performance and the strategies (qualitatively and quantitatively) they applied. Performance scores were computed differently for each task. Strategy use was assessed in two ways: a self-reported scale, with Likert-type items specific to the task, and freely written descriptions of applied strategies elicited with open-ended questions.

Mathematics problem solving test. The mathematical problem "The tank" was inspired by the diagnostic test of difficulties in mathematics, "Test delle abilità di soluzione dei problemi matematici” [Test of abilities in mathematics problem solving] (Lucangeli, Tressoldi, \& Cendron, 1998). New items were added to the original test in order to measure additional variables, the instructions were concurrently modified. Two parallel versions of this problem were used at the immediate and delayed posttests. This instrument is composed of several parts. In the first part, students have to plan out the steps they would need to follow in order to solve the problem. Five steps are suggested and the four correct steps have to be selected and put in order correctly. Students are then invited to solve the problem while writing all of their calculations. In the second part, after solving the problem their strategy use is assessed by 17 Likert-type items pertaining to the selection of information (e.g., underlining), visualizing, result estimation, monitoring, checking, and several surface-level strategies. These items are reduced by principal component analysis into three components: strategy use before solving the task ( $\alpha=.56 ; 4$ items), checking strategy use ( $\alpha=.90 ; 9$ items), and surface-level strategy use $(\alpha=.71 ; 3$ items). The results of these analyses are not reported here as this is not the central focus in the article. Finally, an open-ended question asked the students to report how they attempted to solve the problem ("How did you proceed?"). Their performance was scored according to the number of steps successfully performed by the students (one point per step) and the accuracy of their calculations (one point if all the calculations are correct; otherwise zero points). The processes necessary to the completion of the problem were the same as those involved in the mathematics problems used during the training module.

Text comprehension test. The text comprehension task "The Detectives," developed by Büchel and Molo (2000), was adapted for this project. The task was divided into three parts. First, students read the text and optionally took notes; 10 minutes were allowed for this. Next, students had to answer 11 multiple-choice questions assessing their comprehension of the text without referring directly to the text, but with the help of their notes or memory. Internal consistency of the performance scores was $\alpha=.58$ at pretest, $\alpha$ $=.58$ at immediate posttest, and $\alpha=.69$ at delayed posttest. Büchel and Molo found similar reliability indices with special education students (around $\alpha=.60$ ). Students then completed seven Likert-type items about strategy use (e.g. "After reading the text, I tried to reformulate the text in my own words to check if I had understood," "When I was not able to remember information, I took notes”). The scale was found to be one-dimensional 
and the indices of internal consistency score were $\alpha=.76$ at pretest, $\alpha=.68$ at the immediate posttest, and $\alpha=.67$ at the delayed posttest. Lastly, an open-ended question asked the students to write down the strategy they applied ("What did you do to remember the story and to answer the questions as well as possible?"). At the immediate and the delayed posttests, two parallel versions of the task "the detectives" with exactly the same structure were presented. Individual performance score was based on the number of correct answers in the multiple-choice questionnaire. The tactics crucial to the text comprehension tests were the same to those involved in the text comprehension tasks stressed during the training module.

School-related lesson on DVD. This lesson was designed to assess far transfer effects of the training. The topics of the lessons were biology ("muscles" at the immediate posttest, and "the skeleton" at the delayed posttest). Biology was selected because students should not be experts in the subject chosen and there should not be large inter-individual differences in prior knowledge. No school-related lesson on DVD was administered at the pretest because the goal was to test the transfer of strategies. Therefore, it made little sense to use it before intervention. The lesson procedure began by the experimenter reading some questions related to the topic of the movie to raise students' curiosity and to activate their prior knowledge. Afterwards, the students watched a 20-minute film for the first time. Immediately following, they answered nine open-ended questions assessing comprehension (questions on precise facts were avoided). Then, the film was shown a second time so students could complete their responses if necessary. At the end of the second showing, they were asked to answer a multiple choice questionnaire that contained the same questions as the open-ended questionnaire. They could use their answers to the latter to answer the former. This design was chosen in order to score their responses at different steps of the school-related lesson. After completion of the task, students had to answer to the following open-ended question: "What did you do to understand and to remember the lesson?” to assess applied strategies. Internal consistency of the performance scores, calculated from the number of correct answers to the multiple choice questionnaire, was $\alpha$ (based on standardized items) $=.69$ (8 items) at the immediate posttest, and $\alpha=.71$ (9 items) at the delayed posttest.

Teacher rating of metacognitive control. This scale was inspired by an instrument by Desoete and Roeyers (2006) that asks teachers to evaluate the metacognitive behaviors of their students in mathematics. We translated the items and tailored them for assessment at a general level, rather than at the subject-specific level. Items were reformulated to correspond with the reality of low-track vocational education. This scale contains eight Likert-type items to be answered on a 7-point rating scale (from never to always; e.g., "This student checks his work when he has finished it" and "This student works more slowly and precisely when the exercise is difficult"). Internal consistency of the scores was $\alpha=.93$ at the pretest, $\alpha=.90$ at the immediate posttest, and $\alpha=.93$ at the delayed posttest.

\section{Procedure: Mediation Guide}

The mediation guides were used to structure teachers' interventions. One mediation guide was created for each type of task. They were developed and tested in previous research. To construct these guides, an analysis of the strategies relevant to solving the tasks was made first. Afterwards, questions were formulated to help students identify useful strategies and to motivate them to reflect on their own thinking (i.e., 
metacognitive prompting). The guides were divided into several parts, which referred to the steps basic to the task solution. The examples in Table 5 refer to text comprehension tasks. The use of the mediation guides was taught, for each type of task, during the 5-day course. The teachers were explained the content of the guide, theoretical rationale, and shown some video demonstration/modeling so they could use it properly. Teachers also practiced the use of these guides in small groups through role playing.

Table 5. Extract From the Mediation Guide for Text Comprehension Tasks

1. Introduction to the lesson

The teacher explains the goals of the tasks and the strategies to be developed.

2. Before reading the text

Planning: What will you do to be sure that you understand the text?

3. When reading the text

a) Comprehension: Did you understand what you have read? Could you paraphrase it? What could you do to improve your comprehension?

b) Note taking: What could you do to remember the important information? What is essential to write down when taking notes?

4. After reading the text

Make a drawing: Could you sketch out the story you read?

5. Discussion on the strategies

a) Metacognitive reflection: What were the difficulties of the text? How did you solve the exercise? Which strategy was useful? Which one was not useful?

b) Discussion about the notes taken by the students: Do you think your notes were understandable enough? Were they complete enough? Were they useful?

The guides proved to be useful by helping the teachers prompt their students to use strategies and generally making them more active learners.

\section{Results}

First, we will present descriptive statistics on the cognitive abilities tests for each group. Then, our analyses will focus on the progress in performance as well as the progress in the strategies applied by the students. We center the analyses on the effect of the training on text comprehension, mathematics problem solving, school-related lesson on DVD, and metacognitive control assessed by the teachers.

\section{Scores on the Cognitive Abilities Tests}

Descriptive statistics of the scores on the cognitive abilities test for each group were the following. For non-verbal IQ, the grand mean was $79.81(S D=13.29)$, EG1 $(M=78.97$, $S D=13.44)$, EG2 $(M=79.33, S D=13.03)$, and CG $(M=81.73, S D=13.91)$; for vocabulary knowledge (max. 50 points), the grand mean was $12.88(S D=5.90)$, EG1 ( $M$ $=12.70, S D=4.81)$, EG2 $(M=13.00, S D=6.09)$, and CG $(M=12.95, S D=7.21)$; for arithmetic competencies (max. 24 points) the grand mean was $6.33(S D=4.18)$, EG1 ( $M$ $=6.69, S D=4.85)$, EG2 $(M=5.84, S D=3.75)$, and $C G(M=6.52, S D=3.78)$. The mean IQ was around 80 for the three groups. The mean scores in arithmetic competencies and vocabulary knowledge are very weak, revealing that these tests were too difficult for the students. At the group level, no significant mean differences were 
found for any of the tests. Scores on the cognitive abilities tests were used as covariates in the analyses.

\section{Effect on Text Comprehension: Performance and Applied Strategies}

\section{Performance}

The student performance corresponds to the number of correct answers on the multiple choice questionnaire (z-score). Figure 1 represents the means for each group at the three test phases. Repeated one-tailed ANOVA, with the score in vocabulary knowledge as covariate, were computed. A main effect of the covariate was found, $F(1,51)=15.07$, $p=<.01, \eta^{2}=.23$. Contrast analyses revealed a marginally significant effect of Time $\mathrm{x}$ Group, $F(2,51)=2.41, p=.05, \eta^{2}=.09$, between the immediate and the delayed posttests. Further contrast analyses of this effect revealed significant differences between EG1 and CG, $F(1,36)=3.86, p=.03, \eta^{2}=.10$, and between EG2 and CG, $F(1,30)=$ $3.51, p=.04, \eta^{2}=.11$.

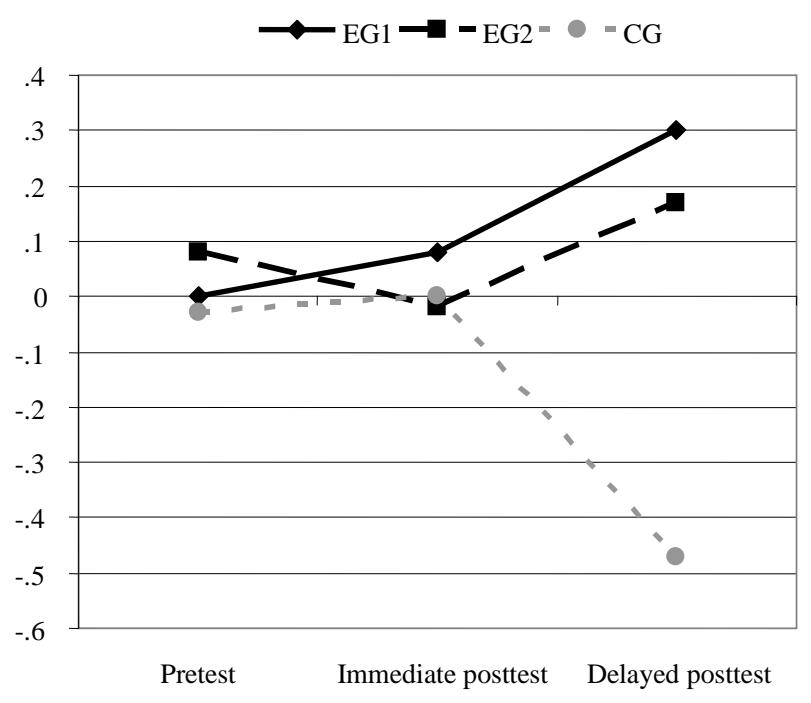

Figure 1. Performance in text comprehension (z-score).

\section{Applied Strategies}

Categorization of the free-writing descriptions revealed that most students mentioned the same two strategies: to read/reread and to take notes. Due to this lack of variability, we did not use this data further. Instead, we assessed strategy use with the Likert-type items related to the task and rated the notes on different criteria to assess any progress in this domain. We used the seven self-reported strategy use Likert-type items that form a single score (see description of the text comprehension test). Figure 2 represents the mean scores for each group at each test phase.

Repeated one-tailed ANOVA, with the score in vocabulary knowledge as covariate, were also computed. A significant interaction effect for Time $\mathrm{x}$ Group, $F(4,76)=2.82, p=$ $.02, \eta^{2}=.13$, was found. The covariate had no significant effect. Contrast analyses revealed that this interaction was significant between pretest and the immediate posttest, $F(2,38)=4.73, p=.02, \eta^{2}=.11$. 


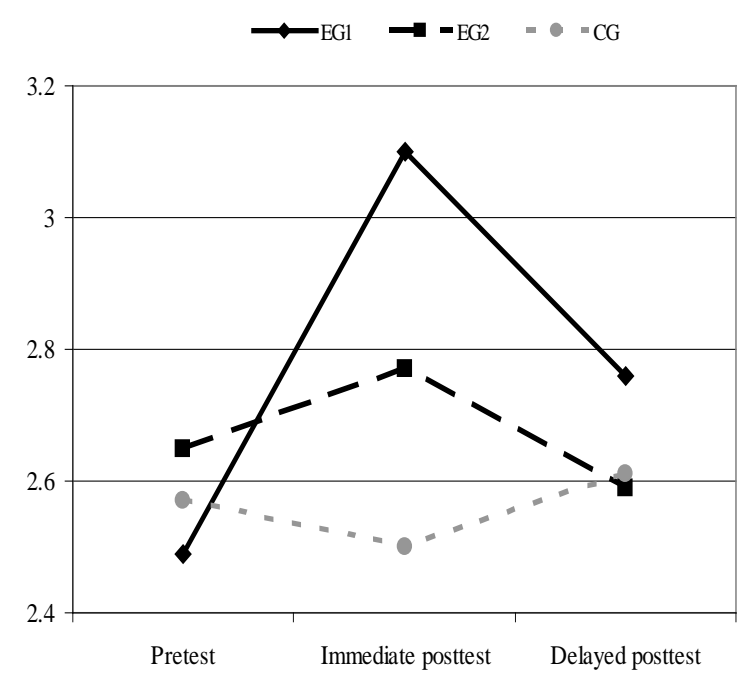

Figure 2. Scores of self-reported strategic behavior in text comprehension (min. = 1 , $\max .=4)$.

Further contrast analyses revealed that the effect was significant between EG1 and CG, $F(1,23)=8.26, p=.01, \eta^{2}=.26$. Moreover, the effect was also significant between EG1 and EG2, $F(1,23)=3.31, p=.04, \eta^{2}=.13$. No difference was found between EG2 and CG. EG1's mean score regressed at the delayed posttest, but did not fall to the initial level, meaning that there is maintenance of the improvement in strategy use.

\section{Effect on Mathematics Problem Solving: Performance and Applied Strategies}

\section{Performance}

The performance in mathematics problem solving corresponds to the number of necessary steps correctly performed by the student. A score of 0 was given to students who did not do any correct steps and a score of 5 was given to students who completed all of the required steps. Figure 3 represents the mean scores for each group at each test phase.

Repeated one-tailed ANOVA, with the score in arithmetic abilities as covariate, were computed. An effect of the covariate was found, $F(1,50)=10.21, p<.01, \eta^{2}=.17$. Contrast analyses revealed a significant effect of Time x Group, $F(2,51)=7.33, p<.01$, $\eta^{2}=.22$, between the pretest and the immediate posttest. Further contrast analyses of this effect revealed that the difference was significant between EG1 and CG, $F(1,36)=$ 14.86, $p<.01, \eta^{2}=.29$. Progression in EG1 was also significantly different from progression in EG2 between pretest and the immediate posttest, $F(1,36)=4.03, p=.03$, $\eta^{2}=.10$. Furthermore, contrast analyses revealed that the progression of the EG2, between the pretest and the immediate posttest, compared to the CG, although not reaching significance level, showed a tendency in the expected direction, $F(1,29)=2.51$, $p=.06, \eta^{2}=.08$. Considering the relatively small sample size and medium effect size, these results are valuable to highlight. The EG1 score regressed slightly between the immediate posttest and the delayed posttest, showing that the improvement was maintained rather well 8 weeks after the training. 


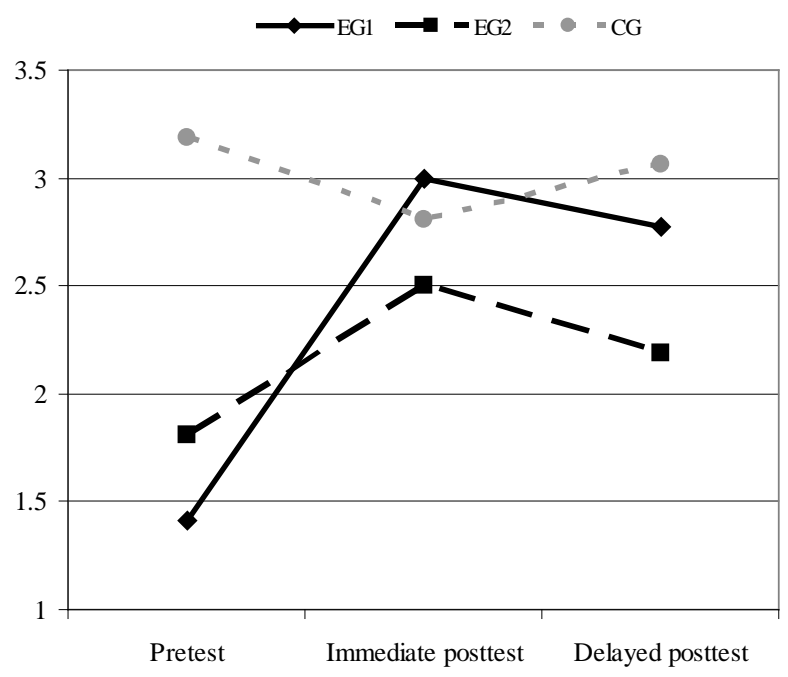

Figure 3. Performance scores in mathematics problem solving (min. $=0$, $\max .=5$ ).

\section{Applied Strategies}

The mean scores on the three components of strategy use (see description of the mathematics problem solving test for the description of the components) did not show much fluctuation from one test phase to the next, so repeated ANOVA revealed no differences between groups. For that reason, we only used the free descriptions written by the students. These descriptions were rated according to a simplified version of the coding scheme proposed by Büchel et al. (2002). This coding scheme distinguishes between five categories: three categories (levels of activity) relative to the strategy described and two categories to qualify answers not related to strategy use. Scores were given according to the level of strategic activity revealed by the description (the interrater agreement on this coding scheme was $\tau=.92, p<.01$ ); the more active the strategy, the higher the score. The five categories with their number of points are the following:

1. Very active or metacognitive strategy (3 points). Examples: "I stopped when I didn't understand." "I made drawings to help myself understand the problem."

2. Active strategy (2 points). Examples: "I proceed step by step." "First, I looked at the numbers and then I proceeded."

3. Passive or naïve strategy (1 point). Examples: "I read it." "With calculations."

4. Deviant answers (0 points). Examples: "With my pencil." "It is good for morale, it is necessary to think a lot."

5. No answer (0 points). The student did not write any answer at all.

If a student mentioned several strategies, the corresponding scores were added and then mean scores for each group were computed for each test phase. Table 6 reports the mean scores of the applied strategy rating for each group, at each test phase. 
Table 6. Mean Scores for the Rating of Free Descriptions of Applied Strategy in Mathematics Problem Solving

\begin{tabular}{cccc}
\hline Group & Pretest & Immediate posttest & Delayed posttest \\
\hline EG1 & 1.46 & 1.88 & 1.73 \\
EG2 & 1.50 & 1.75 & 1.63 \\
CG & 1.41 & 1.33 & 0.82 \\
\hline
\end{tabular}

Repeated one-tailed ANOVA was used and contrast analyses revealed that between pretest and the immediate posttest, a marginally significant effect of Time $\mathrm{x}$ Group was found between EG1 and CG, $F(1,37)=1.81, p=.09, \eta^{2}=.05$. Although this difference was not statistically significant at the $p=.05$ level, it showed a trend and its effect size was medium. Between the immediate posttest and the delayed posttest, this interaction was not additionally significant. As well, no differences were found between the progression of EG2 and CG.

Looking more precisely at the strategies reported by the students, we calculated the percentages for each category. We expected the percentages of active and very active strategies to increase in the two EGs and conversely, the percentages of passive strategies, deviant answers and lack of answers, to decrease. For the CG, the percentages for each category were expected to be relatively stable. Figure 4 reports the percentages of interest.

Inspection of Figure 4 reveals a favorable index of improvement in EG1. The percentage of active strategies increased from pretest to the delayed posttest, while the percentage of "no answer" decreased. Finally, the percentage of very active strategies was rather stable. In the EG2, the pattern was not as favorable. The percentage of deviant answers increased, yet the percentage of active strategies also increased from pretest to the immediate posttest but it largely dissipated at the delayed posttest. In the CG, the percentage of passive strategies largely decreased, but there was a large increase in the "no answer" category.

The strategy types were reduced to three levels in order to calculate a non-parametric test of rank. The following categories were merged: "Deviant answer" with "no answer," and "active strategy" with "very active strategy." The results of Kruskal-Wallis tests of ranks uncovered the following data. At the pretest, there were no differences between the three groups, $\chi^{2}=.36, d f=2$, Asymp. Sig. $=.84$; at the immediate posttest, there were still no significant differences, but there was a tendency for the two EGs to show higher rank, $\chi^{2}$ $=1.92, d f=2$, Asymp. Sig. = .38; at the delayed posttest, the differences were marginally significant, that is, the EG1 had higher rank than EG2 and the latter had higher rank than $\mathrm{CG}, \chi^{2}=3.82, d f=2$, Asymp. Sig. $=.15$. 


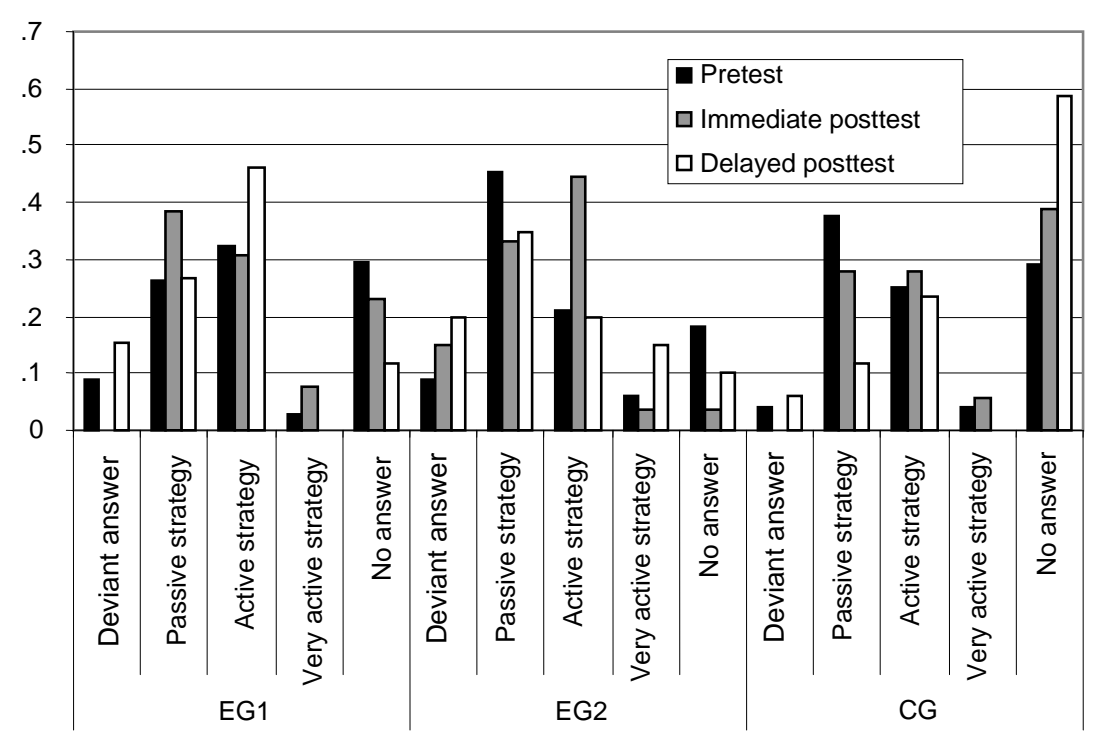

Figure 4. Percentages for each category of strategy relative to mathematics problem solving.

\section{Effect on School-Related Lesson on DVD}

\section{Performance}

We hypothesized that trained students would be more apt to profit from a school lesson than students that did not follow the training. Figure 5 reports the scores for each group at the two test phases.

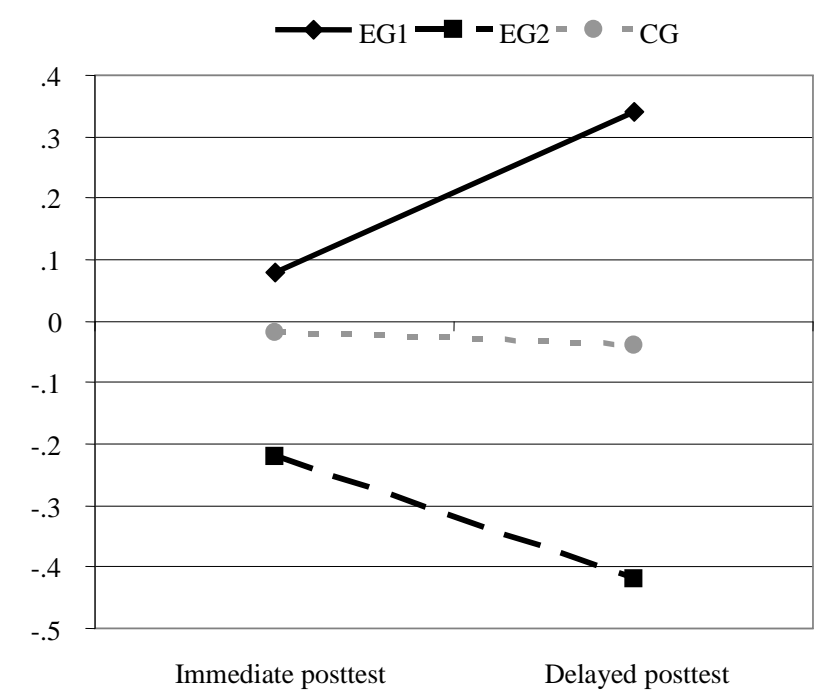

Figure 5. Performance scores in the school-related lesson on DVD (z-score).

At the immediate posttest, EG1 had the highest mean score, but no significant mean differences were found. Analysis of covariance with the immediate posttest score as covariate revealed a significant group effect, $F(2,54)=2.30, p=.05, \eta^{2}=.11$, as well as a covariate 
effect. One-tailed contrast analyses revealed that EG1 did not differ from EG and CG. Nevertheless, the difference between EG1 and EG2 tended toward significance, $p=.07$, but not from the CG, $p=n s$, for both scores. These results show that EG1 performed better, although not significantly, than the CG in the school-related lesson at the immediate posttest (i.e., right after the training). As well, EG1 students showed a greater improvement in their scores in the school-related lesson compared to the students from the two other groups.

In order to explain the low performance by EG2 students, we rated the notes they took during watching the movie (see Table 7). For each correct answer (they knew the questions) two points were given; one point was given for each partially correct answer. For some questions, there were several correct answers.

Table 7. Mean Scores (SDs in parentheses) and $n$ for the Ratings of Notes During the School-Related Lesson on DVD

\begin{tabular}{lcc}
\hline & Rating at immediate posttest & Rating at delayed posttest \\
\cline { 2 - 3 } EG1 & $8.30(3.71)(n=23)$ & $11.48(3.53)(n=25)$ \\
EG2 & $7.74(3.66)(n=23)$ & $12.11(4.65)(n=19)$ \\
CG & $5.41(4.30)(n=17)$ & $10.89(5.43)(n=18)$ \\
Total & $7.32(3.98)(n=63)$ & $11.50(4.44)(n=62)$ \\
\hline
\end{tabular}

Every class's mean score improved substantially. This meant that each of the three groups took more relevant notes (correct answers to the questions) at the delayed posttest. The CG showed the strongest improvement in scores. The performance score correlated significantly (see Table 8) to the rating of the notes for each of the groups at the immediate posttest. However, at the delayed posttest, this correlation was no longer significant for EG 2, $r=.25, p=n s$.

Table 8. Nonparametric Correlations (Kendall's tau; one-tailed) Between Performance in the School-Related Lesson on DVD and Rating of Notes

\begin{tabular}{ccccccc}
\hline & \multicolumn{3}{c}{ Rating at immediate posttest } & \multicolumn{3}{c}{ Rating at delayed posttest } \\
\cline { 2 - 6 } & EG1 & EG2 & CG & EG1 & EG2 & CG \\
\cline { 2 - 7 } & $\begin{array}{c}.53^{* *} \\
\text { Performance in } \\
\text { the lesson }\end{array}$ & $\begin{array}{c}.45^{* *} \\
(n=23)\end{array}$ & $\begin{array}{c}.48^{* *} \\
(n=17)\end{array}$ & $\begin{array}{c}.51^{* *} \\
(n=25)\end{array}$ & $\begin{array}{c}.25 \\
(n=19)\end{array}$ & $\begin{array}{c}.60^{* *} \\
(n=18)\end{array}$ \\
\hline
\end{tabular}

$* * p<.01$.

Our interpretation of these results is that the EG2 did not profit from their notes while answering the multiple choice questionnaire. The other two groups used their notes on both tests. It seems that the low performance of EG2 at the delayed posttest was due to a lack of effort because the students took relevant notes and knew how to use them (as proven by the correlation between the rating of notes and performance at the immediate posttest), but did not use them. This seems to hold true for the four classes composing this group. 


\section{Applied Strategies}

To assess the quality of strategies applied by the students during the school-related lesson on DVD, the same system used for the mathematics problem solving was applied. Rating of the free descriptions was reliable, with an inter-rater agreement (Kendall's tau correlation) of $\tau=.84, p<.01$. Table 9 reports the mean scores of the applied strategy rating for each group at each test phase.

Table 9. Mean scores (SDs in parentheses) and $n$ for the rating of free descriptions of applied strategy in the school-related lesson on DVD

\begin{tabular}{lcl}
\hline & Immediate posttest & Delayed posttest \\
\hline EG1 & $1.95(.59) n=21$ & $2.20(.50) n=25$ \\
EG2 & $2.00(.52) n=23$ & $1.58(.51) n=19$ \\
CG & $1.29(.47) n=17$ & $1.44(.51) n=18$ \\
Total & $1.79(.61) n=61$ & $1.79(.60) n=62$ \\
\hline
\end{tabular}

Looking at the free descriptions of applied strategies, we observed that in EG1, the students reported more active strategies at the delayed posttest than at the immediate posttest. However, this effect was the opposite in EG2 and in the CG, the level of the strategies was rather stable, so the simple repetition of a lesson did not improve the strategies applied. The decline in EG2 was potentially linked to their decline in performance. Considering both, we suspect fatigue had an influence. A one-tailed analysis of covariance, with the immediate posttest score as covariate, revealed that at the delayed posttest, EG1 differed significantly from CG, $F(2,36)=8.50, p<.01, \eta^{2}=$ .20 , and from EG2, $F(2,34)=10.88, p<.01, \eta^{2}=.25$. EG2 scores did not differ significantly from CG scores. Figure 6 reports the percentages of each category of strategy.

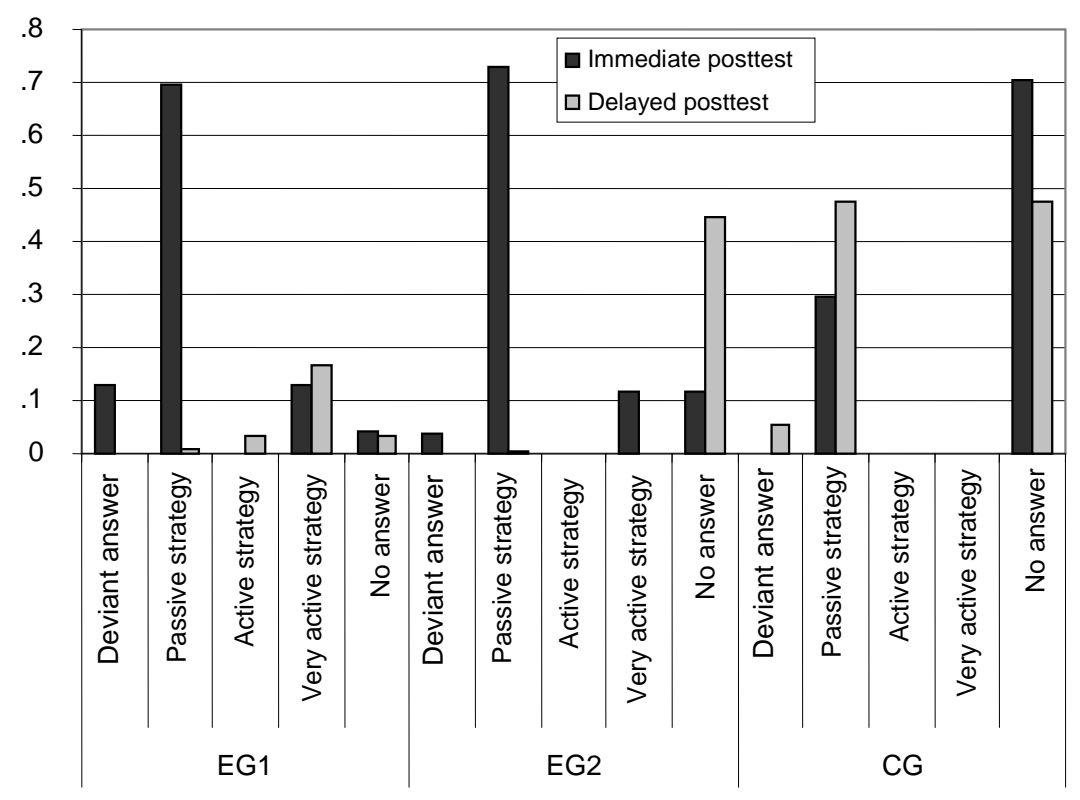

Figure 6. Percentage for each category of strategy relative to schoolrelated lesson on DVD. 
Visual inspection of the figure revealed a favorable index of improvement in EG 1, deviant answers and passive strategies were less frequent while active strategies were more frequent at the delayed posttest. In EG 2, the percentage of deviant answers largely increased between the immediate posttest and the delayed posttest. This was due to a large number of students not answering the question. In the CG, the fluctuations were inconsequential.

The strategy types were reduced to three levels in order to calculate a non-parametric test of rank, as in the mathematics problem solving and the same categories were merged. The results of Kruskal-Wallis tests of ranks revealed that at the immediate posttest, there were significant differences supportive of the two experimental groups; they showed higher mean ranks than the CG, $\chi^{2}=16.42, d f=2$, Asymp. sig. $<.01$. Also, at the delayed posttest, there were significant differences, but the EG 2 had a much lower mean rank, which means the strategies reported were weaker. The difference was between EG1 and CG, $\chi^{2}=19.39, d f=2$, Asymp. sig. $<.01$. Ranks in the CG did not fluctuate much. Taken together, these results showed that EG1 and EG2 strategies were more active than CG strategies at the immediate posttest. EG1 strategies were even more active at the delayed posttest.

\section{Inter-Individual Differences Analyses: Residualized Gain Scores}

To go beyond group comparisons and acknowledge the fact that not all students in the experimental groups profited from the training, we used the method of residualized gain scores to compute a measure of change (Campbell \& Kenny, 1999). Embretson (1987) defined these gain scores in the following terms: "residualized gain is the change that is not predicted by the pre-test and hence reflects gain that is not linearly dependent on the pre-test” (p. 150). These change scores have the strong advantage of avoiding problems due to regression toward the mean. These gain scores were used to distinguish between two kinds of students, those who profited from the training and improved their performances and those who did not. The residual gains were computed for the performance scores (e.g., mathematics problem solving, text comprehension), for strategy use scores (in mathematics problem solving and in text comprehension), and for metacognitive control assessed by the teachers.

For each subject, the gainers were defined as 33\% of students (EG1 \& EG2) showing, between pretest and the immediate posttest, the top residual gains. Analyses of variance were then used to compare the gainers versus the non-gainers. Our interest is in the relationship between improvement in performance, improvement in strategy use, and cognitive abilities. We expect that the students who improve in their performance also improve in strategy applied and vice versa. The link to cognitive abilities is also of interest because it may explain why some students improved and some did not. All the following tests are one-tailed.

In comparison to non-gainers, the gainers in text comprehension showed a significantly higher residualized gain score in strategy use in the same task, $F(1,32)=4.79, p=.01$, $\eta^{2}=.14$. In addition, they demonstrated a higher vocabulary knowledge, $F(1,44)=3.81$, $p=.03, \eta^{2}=.08$. The gainers in mathematics problem solving did not show any higher residual gain in strategy use than the non-gainers. Moreover, they did not differ in their arithmetic abilities. The gainers in metacognitive control (assessed by their teachers) showed a significantly higher residual gain in strategy use in mathematics problem 
solving-both strategy before solving the task, $F(1,26)=3.05, p=.05, \eta^{2}=.11$, and checking strategies, $F(1,26)=6.15, p=.01, \eta^{2}=.19$, and a significantly higher residual gain in strategy use in text comprehension, $F(1,24)=4.77, p=.02, \eta^{2}=.17$. Lastly, the gainers have a higher nonverbal IQ, $F(1,29)=8.11, p<.01, \eta^{2}=.22$, and a higher vocabulary knowledge, $F(1,28)=8.06, p<.01, \eta^{2}=.22$.

\section{Discussion}

This study aimed at evaluating the effects of a metacognitive training module focused on the instruction of metacognitive strategies, metaknowledge, and cognitive strategies to vocational students with learning difficulties. The training was administered by teachers who participated in a 5-day complementary in-service training. The effectiveness of the training module (EG1) has been compared to the application of the principles of the training not structured through a specific module (EG2), as well as, to a group completely unaware of the training (CG). It was expected that EG1 would show superior progress than EG2 and CG in all dependent variables of interest (i.e., performances and strategy use in mathematics problem solving, text comprehension, and a school-related lesson). Furthermore, EG2 was expected to show more progress in these same variables than CG. The results were promising and are synthesized below with reference to the research questions.

The first research question encompassed the effects of the application of the whole training module (EG1) on the students' cognitive and metacognitive strategies, performances, and far transfer effects in a school-related lesson. With respect to far transfer, the results showed that the students improved on their strategies during the training, both in mathematics problem solving (see Table 6 and Figure 4) and in text comprehension (see Figure 2). This was observed in self-reported Likert-type items and in free-writing descriptions of applied strategies. This improvement was clearly maintained 8 weeks after the training. In regard to performance, a large improvement in both school subjects and maintenance of the performance level 8 weeks later was observed (see Figures 1 and 3). In relation to far transfer to a school-related lesson, EG1 students demonstrated a higher level of comprehension (see Figure 5) and reported more active strategies than EG2 and CG students (see Table 9 and Figure 6). This indicates that they became more active learners not only in the tests we administered but also in a school-related lesson. A practical implication of these results is that systematic metacognitive prompting in vocational education courses may be truly beneficial for slow learners' cognitive functioning.

The second research question covered the effects of the non-explicit application of metacognitive training (EG2) on the students' cognitive and metacognitive strategies, performance, and far transfer effects in a school-related lesson. In other words, this question concerned the implicit effect of the 5-day teacher training. The results showed that the effects were less important than for EG1. Albeit smaller than in EG1, significant improvements were observed in mathematics problem solving (see Figure 3) and text comprehension (see Figure 1) performance. Pertaining to strategy use, EG2 students' free descriptions of applied strategies in mathematics problem solving showed significant improvement between the pretest and the immediate posttest (see Table 6 and Figure 4). This progress was maintained 12 weeks after the immediate posttest. 
The third research question explored inter-individual differences in improvement, with focus on performance and strategy use. An association was found between improvement in performance and improvement in strategy use (from both the student perspective and the teacher perspective). In addition, the students showing the most improvement in training were the same students who had demonstrated the highest scores on cognitive abilities tests at the beginning of the training (in terms of arithmetic abilities, non verbal intelligence and vocabulary knowledge). These results are interpreted as a Matthew effect, as found in most training studies (Flammer, 1975).

Our general conclusion is that teachers guided by the highly structured 12-week training module (with rotating decontextualized and school tasks) improved their students' performance and strategies significantly. However, teachers in EG2 certainly did not give as many of the 12 lessons as they initially promised, and they used the principle of rotation noticeably less. We hypothesize that the duration of the training is at least partly responsible for the differences in progress between EG1 and EG2. Moreover, with EG2 students, the intervention showed a lack of face validity, most likely caused by a lack of rotation between decontextualized and school-related tasks. Regarding the length of cognitive training, we are increasingly convinced that a critical number of lessons is an absolute condition for successful learning, maintenance, and transfer (Büchel 2007; Büchel \& Scharnhorst, 1993). Students need time to become aware of their own learning style (metacognitive phase) and they need additional time to optimize previously acquired strategies or replace them with new ones if necessary. Another problem was that some teachers were not able to convince their students of the value of decontextualized tasks; therefore, these students did not profit sufficiently from the strategy acquisition phase of the training. As well, other teachers failed to adequately foster the transfer of strategies. All of the stated difficulties are related to the nature of the study, which took place in a natural setting (field study) in which little control over these factors was possible. Conversely, ecological validity of the results is supported by the practical implications of the results.

Additional limits of this research include the number of classes taking part in the research, which was fewer than expected. Although this number was small, there were still enough to study the effects of the training, though a generalization of the results is nevertheless limited. More to the point, we had little control over the content of the training in EG2, so we lacked information to interpret the differences in results between EG1 and EG2 meticulously. Further research should account for this problem, and a homogenous (in terms of content and length) alternative training should be contrasted with the cognitive education intervention module.

Future oriented research should focus on the transfer of metacognitive strategies and cognitive strategies from the school setting to the workplace, since our study was limited to the school. This would provide a feeling of utility for students and thus make cognitive and metacognitive strategies more valuable. Furthermore, the ecological validity of our intervention model could thus be enhanced. 


\section{References}

American Psychiatric Association (1994). Diagnostic and statistical manual of mental disorders ( $4^{\text {th }}$ ed.). Washington, DC: American Psychiatric Association.

Bandura, A. (1997). Self-efficacy: The exercise of control. New York: Freeman.

Borkowski, J. G., Chan, L. K. S., \& Muthukrishna, N. (2000). A process-oriented model of metacognition: Links between motivation and executive functioning. In G. Schraw (Ed.), Issues in the measurement of metacognition (pp. 1-41). Lincoln, NE: Buros Institute.

Borkowski, J. G., \& Day, J. D. (1987). Research with special children: Issues, definitions and methodologies. In J. G. Borkowski \& J. D. Day (Eds.), Cognition in special children: Comparative approaches to retardation, learning disabilities, and giftedness (pp.1-14). Norwood, NJ: Ablex.

Borkowski, J. G., Reid, M. K., \& Kurtz, B. E. (1984). Metacognition and retardation: Paradigmatic, theoretical, and applied perspectives. In P. H. Brooks, R. Sperber,\& C. McCauley (Eds.), Learning and cognition in the mentally retarded (pp. 55-75). Hillsdale, NJ: Erlbaum.

Brown, A. L. (1978). Knowing when, where, and how to remember: A problem of metacognition. In R. Glaser (Ed.), Advances in instructional psychology (Vol. 1, pp. 77-165). Hillsdale, NJ: Erlbaum.

Brown, A. L. (1987). Metacognition, executive control, self-regulation, and other more mysterious mechanisms. In F. E. Weinert \& R. H. Kluwe (Eds.), Metacognition, motivation, and understanding (pp. 65-116). Hillsdale, NJ: Erlbaum.

Büchel, F. P. (2003). Les processus d'apprentissage chez des personnes ayant un retard mental ou des difficultés d'apprentissage: quelles théories, quelles recherches? [Learning processes in people with mental retardation or learning difficulties: What theories, what research?] In G. Chatelanat \& G. Pelgrims (Eds.), Education et enseignement spécialisés: ruptures et intégrations (pp. 121-154). Bruxelles, Belgium: de Boeck.

Büchel, F. P. (2007). L'intervention cognitive en éducation spéciale. Deux programmes métacognitifs [Cognitive intervention in special education. Two metacognitive programs]. Genève: Collection carnets des sciences de l'éducation.

Büchel, F. P., \& Büchel, P. (1997). DELV: A metacognitive programme for adolescents and adults. In J. H. M. Hamers \& T. Overtoom (Eds.), Teaching thinking in Europe (pp. 45-49). Utrecht, The Netherlands: Sardes.

Büchel, F. P., Grassi, A., Scharnhorst, U., \& Ghilardi, M. (2002). Die Evaluation des DELV-Programmes bei Schülerinnen und Schülern in der beruflichen Ausbildung [Evaluation of the program DELF with vocational students]. Zollikofen, CH: SIBPSchriftenreihen Nummer 16.

Büchel, F. P., \& Molo, P. (2000, October). Stratégies de contrôle métacognitif dans la lecture chez les élèves de l'enseignement spécialisé. Une étude descriptive et interventive [Metacognitive reading strategies in special education students. A descriptive and intervention study]. Actes des Journées d'étude sur la formation et les apprentissages de la personne déficiente intellectuelle. Château de Colonster, Liège, Belgium.

Büchel, F. P. \& Scharnhorst, U. (1993). Training des induktiven Denkens bei Lern- und Geistigbehinderten [Training of inductive thinking in children with learning difficulties or mental retardation]. In K. J. Klauer (Ed.). Kognitives Training (pp. 95-123). Göttingen, Germany: Hogrefe. 
Büchel, F. P., \& Scharnhorst, U. (2000). Strategy training in students with learning difficulties or mental retardation. General or specific, content rich or content free, contextualized or decontextualized? Paper presented at the $3^{\text {rd }}$ European Conference on Psychological Theory and Research on Mental Retardation, Geneva, Switzerland.

Campbell, D. T., \& Kenny, D. A. (1999). A primer on regression artifacts. New York: Guilford.

Cavanaugh, J. C., \& Perlmutter, M. (1982). Metamemory: A critical examination. Child Development, 53, 11-28.

Deltour, J. J. (1998). Echelle de vocabulaire Mill-Hill de J. C. Raven [J. C. Raven’s MillHill vocabulary test]. Paris: Editions et Applications Psychologiques.

Desoete, A., \& Roeyers, H. (2006). Metacognitive macroevaluations in mathematical problem solving. Learning and Instruction, 16, 12-25.

Elke, A., Grieder, S., Tiaden, C., Steiner, G., Metzger, C., Nüesch, C., Büchel, F. P., Berger, J.-L., \& Kipfer, N. (in press). Fostering learning competences in vocational education, Leading House Basel. Proceedings der Göttinger Tagung, September 25 - 28, 2007 in Göttingen, Germany.

Embretson, S. E. (1987). Toward development of a psychometric approach. In C. S. Lidz (Ed.), Dynamic assessment: An international approach to evaluating learning potential (pp. 141-170). New York: Guilford.

Equipe CogEd (2005). Problème de mathématiques Camping des Alpes 5P-6P [Mathematics problem "Alps Campsite" for $5^{\text {th }}$ and $6^{\text {th }}$ grades]. Unpublished test, Université de Genève, Genève.

Feuerstein, R., Feuerstein, Ra., \& Schur, Y. (1997). Process as content in education of exceptional children. In A. Kozulin (Ed.), The ontogeny of cognitive modifiability. Applied aspects of mediated learning experience and Instrumental Enrichment (pp. 1-24). Jerusalem: International Center for the Enhancement of Learning Potential.

Feuerstein, R., Rand, Y., Hoffman, M. B., \& Miller, R. (1980). Instrumental Enrichment. An intervention program for cognitive modifiability. Baltimore: University Park Press.

Flammer, A. (1975). Individuelle Unterschiede im Lernen [Interindividual differences in learning]. Weinheim, Germany: Beltz.

Flavell, J. H. (1971). First discussant's comments: What is memory development the development of? Human Development, 14, 272-278.

Flavell, J. H. (1976). Metacognitive aspects of problem solving. In L. B. Renick (Ed.), The nature of intelligence (pp. 231-235). Hillsdale, NJ: Erlbaum.

Flavell, J. H., \& Wellman, H. M. (1977). Metamemory. In R. V. Kail \& J. W. Hagen (Eds.), Perspectives on the development of memory and cognition (pp. 3-33). Hillsdale, NJ: Erlbaum.

Graham, S., \& Harris, K. R. (2005). Writing better: Effective strategies for teaching students with learning difficulties. Baltimore, MA: Paul H. Brookes.

Hoffman, B., \& Spatariu, A. (2008). The influence of self-efficacy and metacognitive prompting on math problem-solving efficiency. Contemporary Educational Psychology, 33, 875-893.

Klauer, K. J. (2002). A new generation of cognitive training for children: A European perspective. In G. M. van der Aalsvoort, W. C. M. Resing, \& A. J. J. M.

Ruissenaars (Eds.), Learning potential assessment and cognitive training. Actual research and perspectives in theory building and methodology (pp. 147-174). Amsterdam: Elsevier. 
Klauer, K. J., \& Phye, G. D. (1994). Cognitive training for children. A developmental program of inductive reasoning and problem solving. Seattle: Hogrefe \& Huber.

Lobeck, A. (1990). Rechentest 4-6 Klasse [Calculation test for grades 4 to 6]. Basel, Switzerland : Beltz Test.

Lucangeli, D., Tressoldi, P. E., \& Cendron, M. (1998). SPM: Test delle abilità di soluzione dei problemi matematici [SPM: Test of abilities in mathematics problems solving]. Spini di Gardolo, Trento, Italy: Erickson.

Masi, G., Marcheschi, M., \& Pfanner, P. (1998). Adolescents with borderline intellectual functioning: Psychopathological risk. Adolescence, 33, 415-424.

Mevarech, Z. R., \& Fridkin, S. (2006). The effects of IMPROVE on mathematical knowledge, mathematical reasoning and meta-cognition. Metacognition and Learning, 1, 85-97.

Montague, M. (1998). Research on metacognition in special education. In T. E. Scruggs \& M. A. Mastropieri (Eds.), Advances in learning and behavioral disabilities (Vol. 12, pp. 151-183). Greenwich: JAI.

Montague, M. (2007). Self-regulation and mathematics instruction. Learning Disabilities Research \& Practice, 22, 75-83.

Naglieri, J. A. (1998). Test d'aptitude non verbale de Naglieri [Naglieri nonverbal achievement test]. Paris: Editions du Centre de Psychologie Appliquée.

Pressley, M., Goodchild, F., Fleet, J., Zajchowski, R., \& Evans, E. D. (1989). The challenges of classroom strategy instruction. The Elementary School Journal, 89, 301-342.

Schmid, E., \& Stalder, B. E. (2007). Lehrvertragsauflösung: direkter Wechsel und vorläufiger Ausstieg Ergebnisse aus dem Projekt LEVA [Results of the LEVA project on immediate reorientation and temporary exit of the system]. Berne, Switzerland: Bildungsplanung und Evaluation der Erziehungsdirektion des Kantons Bern.

Swanson, H. L. (1993). Executive processing in learning-disabled readers. Intelligence, 17, 117-149.

Van Luit, J. E. H., \& Kroesbergen, E. H. (2006). Teaching metacognitive skills to students with mathematical disabilities. In A. Desoete \& M. V. J. Veenman (Eds.), Metacognition in mathematics education (pp. 177-190). New York: Nova Science.

Veenman, M. V. J., \& Beishuizen, J. J. (2004). Intellectual and metacognitive skills of novices while studying texts under conditions of text difficulty and time constraint. Learning and Instruction, 14, 621-640.

Weinstein, C. E., Husman, J., \& Dierking, D. R. (2000). Self-regulation interventions with a focus on learning strategies. In M. Boekaerts, P. R. Pintrich, \& M. Zeidner (Eds.), Handbook of self-regulation (pp. 727-747). San Diego, CA: Academic Press.

Wong, B. Y. L (1993). Pursuing an elusive goal: Molding strategic teachers and learners. Journal of Learning Disabilities, 26, 354-357. 


\section{Appendix}

Poisson
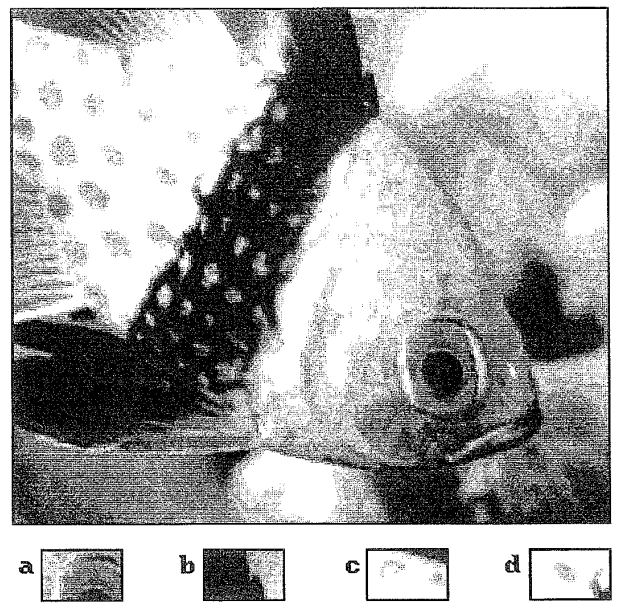

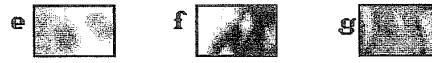

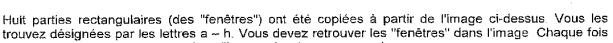

ocopyight 1995

\section{Example Windows from DELF program}

Instructions: Eight rectangular parts (windows) have been copied from the above picture. You have to find the windows in the picture. Each time you recognize one in the picture, draw a frame on it.

Figure A1. Task from the DELF's Windows (Büchel \& Büchel, 1997).

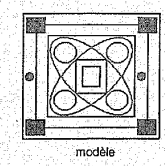

Orbites encadrées
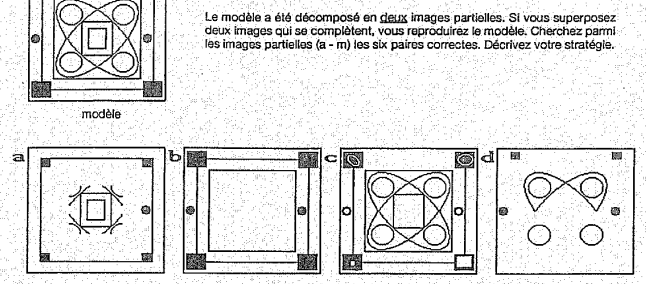

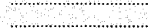
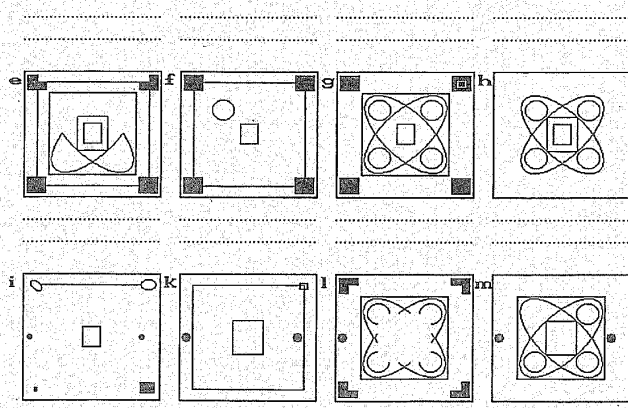

Example Broken up figures from DELF program Instructions: The model has been broken up in two partial figures. If you place two of the pictures on top of each other, you will reproduce the model. Find among the partial pictures (a-m) the six correct pairs. Describe your strategy.

Figure A2. Task from the DELF’s Broken up figures (Büchel \& Büchel, 1997). 


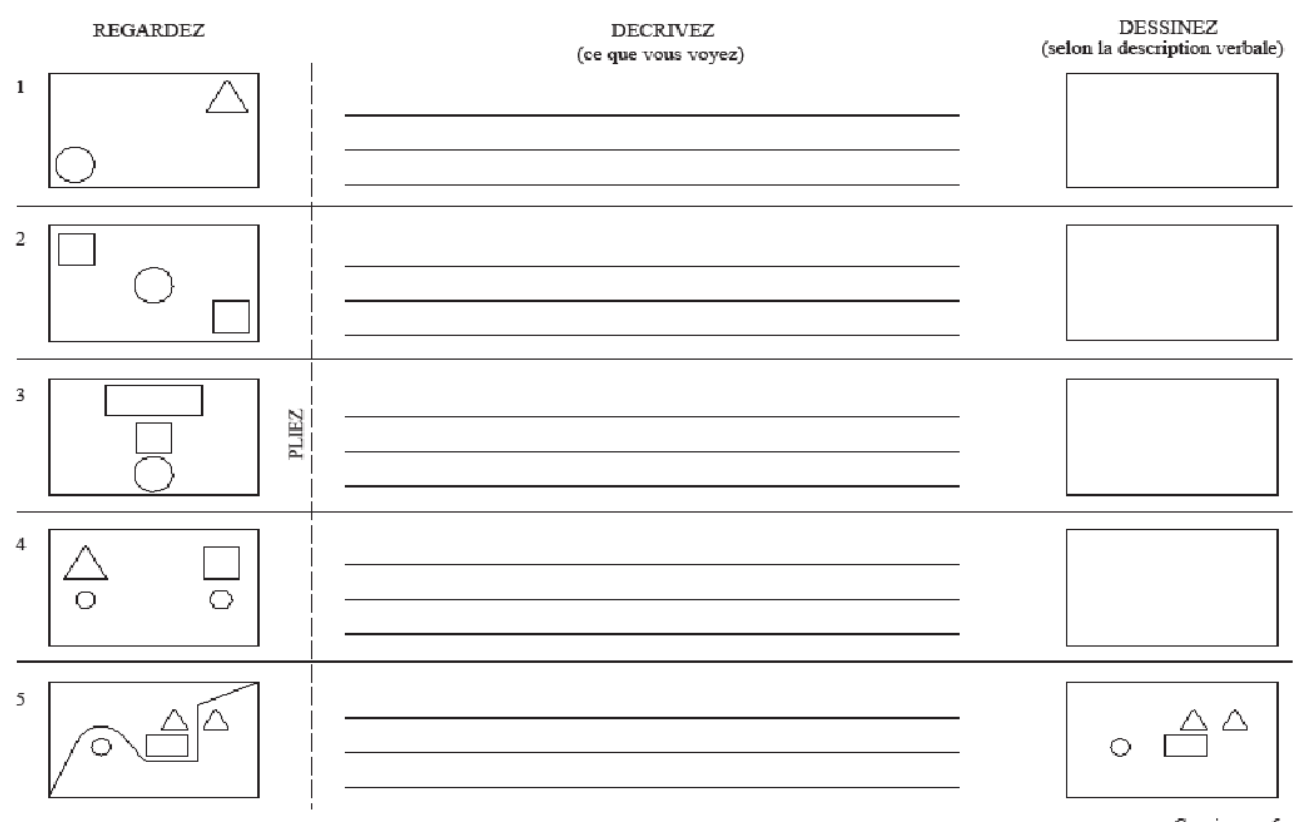

Figure A3. Task from IE’s Instructions instrument (Feuerstein, Rand, Hoffman, \& Miller, 1980).

\section{“Alps” Campsite}

Mr. and Mrs. Perrin stayed at the “Alps” campsite from August 28 to September 3. They traveled by car and were accompanied by their three children, Marie, Pierre and Nicolas, aged 7, 13 and 12, and with their dog, Archibald.

They had two camping tents, a large one and a small one. They have to pay for each tent site.

They gave 200 Swiss francs to the campsite manager. How much change will they get in return?

\begin{tabular}{|l|l|l|}
\hline \multicolumn{3}{|c|}{ Price list (per day) } \\
\hline & High season & Low season \\
\hline Large tent & 4 CHF & 3 CHF \\
\hline Small tent & 3 CHF & CHF \\
\hline Adult & 6 CHF & 5 CHF \\
\hline Child & CHF & 2 CHF \\
\hline Car & 2 CHF & 1 CHF \\
\hline \multicolumn{3}{|c|}{ High season : July and August } \\
Low season : All other months
\end{tabular}

Figure A4. Mathematics problem used in the training (Equipe CogEd, 2005). 


\section{Author Note}

This research was funded by the Swiss Federal Office for Professional Education and Technology. The authors acknowledge the valuable editorial support of Laura LoderBüchel, Teacher Training College, Schaffhausen, Switzerland.

\section{Address for correspondence:}

Dr Jean-Louis Berger is now at:

University of Michigan

Combined Program in Education and Psychology

1400-3 School of Education

610 East University Avenue

University of Michigan

Ann Arbor, MI 48109-1259

bergerjl@umich.edu

Dr Nadine Kipfer, Swiss Pedagogical Institute for Vocational Training, Avenue de Provence 82, 1007 Lausanne, Switzerland.

nadine.kipfer@iffp-suisse.ch

Prof. Dr Fredi Büchel, Faculty of Psychology and Educational Sciences, University of Geneva, Boulevard du Pont d'Arve 40, 1205 Genève, Switzerland.

fredi.buchel@unige.ch 